\title{
Cancer-associated fibroblasts regulate the biological behavior of cancer cells and stroma in gastric cancer (Review)
}

\author{
QIAN ZHANG ${ }^{1}$ and CHUNWEI PENG ${ }^{2}$ \\ ${ }^{1}$ Department of The Second Clinical College, Wuhan University; ${ }^{2}$ Department of Oncology, \\ Zhongnan Hospital of Wuhan University, Hubei Key Laboratory of Tumor Biological Behaviors \\ and Hubei Cancer Clinical Study Center, Wuchang, Wuhan 430071, P.R. China
}

Received January 15, 2017; Accepted September 28, 2017

DOI: $10.3892 / \mathrm{ol} .2017 .7385$

\begin{abstract}
Gastric cancer (GC) is a frequently diagnosed type of cancer in China, and is associated with a high mortality rate. The biological behavior of GC requires investigation in order to provide an evidence base for the development of strategies to prevent and treat GC. For this purpose, the present review outlines the process of tumor microenvironment (TME) evolution, including the dynamic biological behavior of different types of cancer cell and stroma. Cancer-associated fibroblasts (CAFs) serve as prominent stromal cellular components in the GC TME, and exhibit an essential function in GC progression. In the present study, the function of CAFs in cancer cell proliferation, cell migration, invasion, extracellular matrix remodeling, pathological angiogenesis and immune cell infiltration were investigated. The studies discussed in the present review demonstrate that the cross-talk between CAF, cancer cells and tumor stroma promotes GC progression.
\end{abstract}

\section{Contents}

1. Introduction

2. CAFs regulate the biological behavior of GC cells

3. CAFs regulate the biological behavior of the stroma

4. Conclusion and prospects

\section{Introduction}

Gastric cancer (GC) is one of the four most common types of cancer in China, and is associated with a high mortality

Correspondence to: Dr Chunwei Peng, Department of Oncology, Zhongnan Hospital of Wuhan University, Hubei Key Laboratory of Tumor Biological Behaviors and Hubei Cancer Clinical Study Center, 169 Donghu Road, Wuchang, Wuhan 430071, P.R. China

E-mail: whupengcw@whu.edu.cn

Key words: cancer-associated fibroblast, vascular endothelial growth factor, gastric cancer, angiogenesis, tumor microenvironment rate. Between 33 and $50 \%$ of worldwide GC diagnoses occur in China (1). GC exhibits significant heterogeneity regarding its biological behavior and results in differing prognoses, independent of clinical stage (2). Despite cancer cells being extensively studied, advances in cancer research have highlighted that cancer progression is primarily determined by individual biological behaviors that are modulated via the cross-talk between cancer cells and the tumor microenvironment (TME) (3). Numerous studies have demonstrated the pivotal function of TME in GC progression (4-6). TMEs are heterogeneous in nature, containing a surrounding extracellular matrix (ECM) and several different types of cell including fibroblasts, endothelial cells, immune cells, local and bone marrow-derived stromal stem and progenitor cells (7). In the present review, the current knowledge of cancer-associated fibroblasts (CAFs), which are important components in the TME, are summarized in order to elucidate the exact function(s) of CAFs in the regulation of different biological behaviors which occur in GC progression (8-11).

CAFs are spindle-shaped blast-like cells with an unclear origin; however, a previous study demonstrated that bone marrow-derived stromal cells are a major source of CAFs, as well as mesenchymal stem cells (MSCs) (12). Several factors mediate the differentiation of CAFs, and certain markers, including $\alpha$-smooth muscle actin ( $\alpha$-SMA), fibroblast activation protein (FAP) and platelet-derived growth factor (PDGF) receptor $\alpha / \beta$, have been used to distinguish $\mathrm{CAF}$ from other types of fibroblast (Fig. 1) (10,13-15).

\section{CAFs regulate the biological behavior of GC cells}

CAFs promote GC cell proliferation. The interaction between cancer cells and adjacent stroma may motivate specific TMEs to promote GC tumor progression $(16,17)$. Accumulating evidence has suggested that CAFs may increase the proliferation rate of GC cells through a variety of mechanisms, for example by targeting PTEN via microRNA-106b in CAFs or by targeting the TGF- $\beta /$ Smad pathway $(18-21)$. It has been demonstrated previously that bone marrow-derived fibrocytes may migrate into the GC TME using the stromal cell-derived factor 1 (SDF-1)/CXC chemokine receptor type 4 (CXCR4) system, and may increase cancer cell proliferation and the rate of fibrosis, in a similar manner to CAFs (18). In addition, 
Han et al (22) demonstrated that neuregulin 1, secreted by GC stem cells (GCSCs), regulated the activation of the nuclear factor $\kappa \mathrm{B}(\mathrm{NF}-\kappa \mathrm{B})$ signaling pathway, and modulated the proliferation and invasion of GC cells by culturing GCSCs and CAFs directly from patients with GC. Kikuchi et al (23) demonstrated that periostin (POSTN) was overexpressed due to CAF, and POSTN may regulate the primary tumor niche by supporting cancer cell proliferation through the extracellular-signal-related kinase (ERK) signaling pathway in GC when testified in the mouse fibroblast cell line NIH3T3 C57BL/6 POSTN $^{-/}$and human diffuse-type GC cell lines OCUM-2MLN and OCUM-12.

CAFs promote GC cell migration and invasion. CAFs directly and indirectly improve the ability of invasion and metastasis, fundamental behaviors in cancer cells $(24,25)$. CAFs are able to induce an aggressive phenotype and cause functional changes in GC cells in order to enhance the ability of cells to invade directly. This biological behavior is termed the epithelial-mesenchymal transition (EMT) (12). It has been reported previously that HSC-39 cells modulate EMT by communicating with CAFs during the process of cancer metastasis (26). Tsukada et al (27) demonstrated, using a GC mouse xenograft model, that human peritoneal mesothelial cells may be an origin of CAFs, and are activated by transforming growth factor $\beta$ (TGF $\beta$ )-1 signaling, leading to the acquirement of the ability to invade basement membranes in GC.

In addition to the direct effects of CAFs on GC cells, accumulating evidence focused primarily on the invasion ability of GC cells has demonstrated that CAFs are able to indirectly improve the ability of GC cells to invade and metastasize by secreting numerous functional molecules $(24,25,27)$. Yang et al (19) used conditioned media from CAFs and normal fibroblasts (NFs) to stimulate GC cells, and demonstrated that GC cell invasion rates were significantly increased in the CAF group compared with the NF group. Furthermore, by utilizing a co-culturing system containing chromatic assembly factor 1 and atypical glandular cells (gastric cell line) as an in vitro model for an invasion study, Fukui et al (28) demonstrated that interleukin (IL)-22 is produced by CAFs and promotes GC cell invasion via signal transducer and activator of transcription 3 and ERK signaling pathways. Similarly, He et al (29) co-cultured GC cells with CAFs that were transfected with galectin (Gal)-1 small interfering RNA, and demonstrated that CAFs increased the capability for GC cells to migrate into and invade the stroma through the overexpression of Gal-1 protein. Sun et al (30) demonstrated that glia-activating factor 9 secreted from CAFs may upregulate the expression of matrix metalloproteinase (MMPs) dose-dependently, and resulted in an increase in the number of invasive cells. Results from a previous study suggest that the proportion of CAFs in scirrhous GC is increased and results in a poor clinical prognosis as cancer cells are able to invade the submucosa, which contains an abundance of stromal cells (21). Additionally, Sung et al (31) demonstrated that the expression of Twist-related protein 1 was observed more frequently in GC CAFs compared with other cells, and also led to a significant increase in the invasive ability of GC cells in vitro.

It is well-known that cancer cells generate a supportive microenvironment in order to activate fibroblasts and facilitate the secretion of growth factors and proteases at the peritoneal dissemination site through numerous stroma-modulating growth factors, including fibroblast growth factor (FGF) family members, PDGF, vascular endothelial growth factor (VEGF) family members, epidermal growth factor ligands, ILs and TGF- $\beta 1$ (32-34). Comparatively, the potential invasive and metastatic ability of cancer cells may be enhanced by the transdifferentiation process via EMT. In this process, MSCs promote tumor growth by differentiating into CAFs and remodeling the TME, and facilitate invasion and metastasis observed in GC $(20,35)$. Karnoub et al (36) compared growth kinetics between MSC-containing tumors [breast cancer cells (BCCs) and MSCs]. BCCs were injected into a xenograft model of immunocompromised mice, and results demonstrated that chemokine ligand 5-chemokine receptor 5 paracrine interactions serve a pivotal function in the process of enabling MSCs to induce metastasis. Furthermore, a previous study suggested that MSCs acquired a CAF phenotype when exposed to GC-derived exosomes, and the differentiation of MSCs to CAFs was associated with the activation of the TGF- $\beta / \mathrm{Smad}$ signaling pathway (20). Additionally, this study demonstrated that tumor exosomes are able to promote the migration of human umbilical cord MSCs in vitro. Xu et al (37) demonstrated that MSC-like cells are able to be isolated from human GC tissues (hGC-MSCs) and adjacent non-cancerous tissues (hGCN-MSCs) from the same patient, and results demonstrated several characteristic discrepancies between the cell surface markers, the pluripotency and the proliferation-associated gene expression in these two cell types. Notably, another study used a Transwell migration assay to confirm the difference in the migration abilities of hGCN-MSCs and hGC-MSCs, which may partially result from the difference in the cluster of differentiation (CD) 44 expression level, as CD44 is one of the most important adhesion molecules and serves a crucial function in cell migration and invasion processes (38). Tsukada et al (27) demonstrated that TGF- $\beta$, derived from cancer cells in the peritoneal TME was able to activate human peritoneal mesothelial cells (HPMCs) and lead to the progression and fibrosis of GC. However, it was suggested that HPMCs are one of the origins of CAFs and contribute to the EMT mechanism (26). Yu et al (39) demonstrated that CAFs promoted GC cell migration and invasion by upregulating transgelin (TAGLN) levels and TAGLN-induced MMP-2 production in human GC stroma. Furthermore, it was also demonstrated that TAGLN promoted tumor metastasis by upregulating MMP-2 enzymes that are capable of degrading the basement membrane.

\section{CAFs regulate the biological behavior of the stroma}

Interaction between CAFs and ECM in GC. Cancer is a highly complex process, involving numerous cancer cells and the surrounding stroma, which is constructed of various different types of mesenchymal cell and the ECM (40). The ECM is a complex ecosystem scaffold populated by different types of stromal cell, including fibroblast-like cells, endothelial cells and immune cells, and is morphologically defined by desmoplasia, angiogenesis, inflammation and the immune response $(41,42)$. Histopathological and genetic evidence suggests that tumor-associated stromal proportions or signatures may refine the prognostic assessment of tumors, therefore CAF-induced 


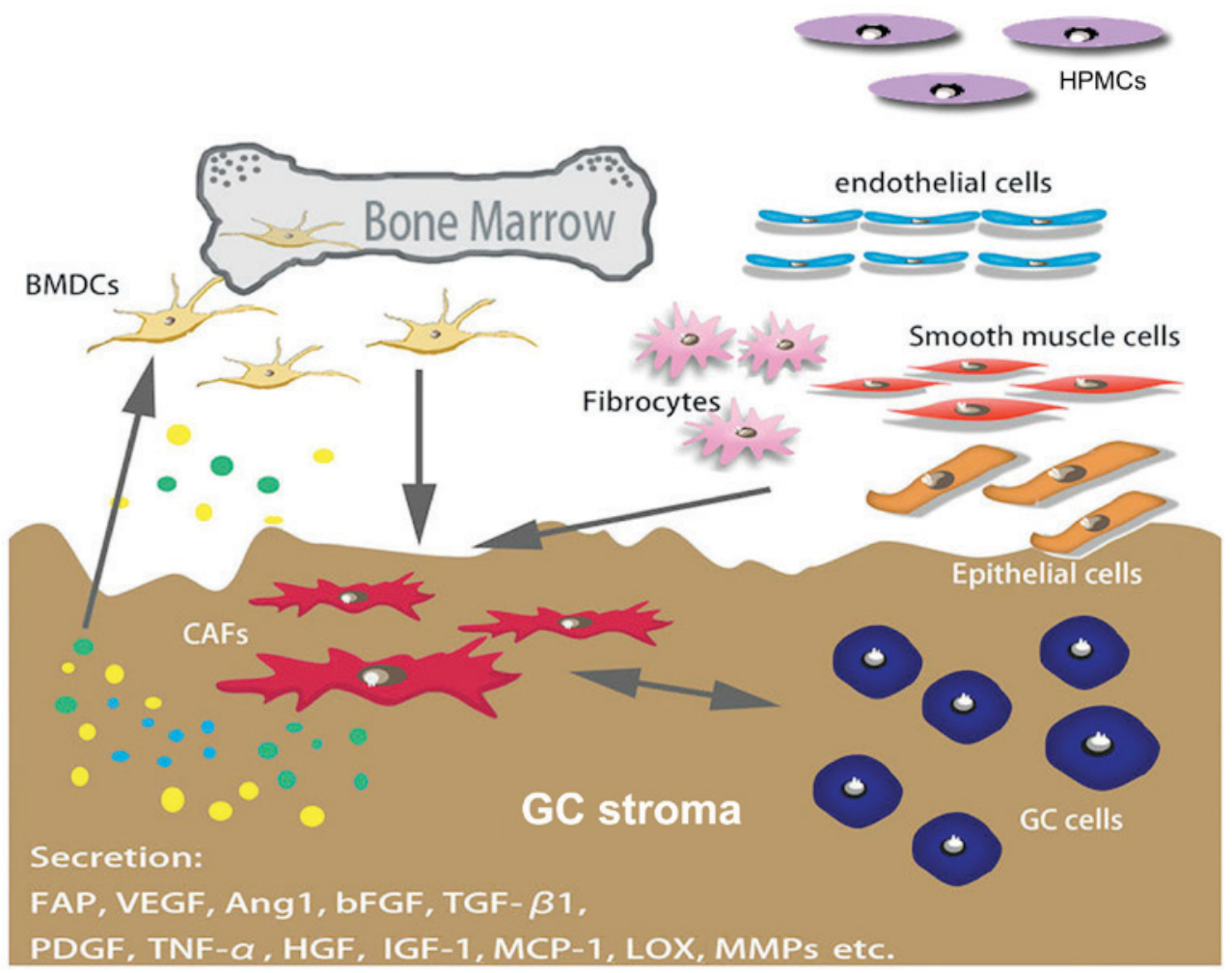

Figure 1. Origination of CAFs in GC. Numerous types of cells are able to differentiate into CAFs, including BMDCs, smooth muscle cells, endothelial cells, fibrocytes and epithelial cells. BMDCs are a major source of CAFs. Several factors secreted by cancer cells mediate the differentiation of CAFs, and certain markers (including $\alpha$-smooth muscle actin, FAP and PDGF receptor $\alpha / \beta$ ) have been used to distinguish CAFs from other types of fibroblasts. CAFs, cancer-associated fibroblasts; GC, gastric cancer; BMDCs, bone marrow-derived cell; FAP, fibroblast activation protein; PDGF, platelet-derived growth factor; HPMCs, human peritoneal mesothelial cells; VEGF, vascular endothelial growth factor; Ang1, angiopoietin 1; bFGF, basic fibroblast growth factor; TGF- $\beta 1$, transforming growth factor $\beta 1$; TNF- $\alpha$, tumor necrosis factor- $\alpha$; HGF, hepatocyte growth factor; IGF-1, insulin-like growth factor; MCP-1, monocyte chemoattractant protein-1; LOX, lysyl oxidase; MMPs, matrix metalloproteinases.

desmoplasia may serve a pivotal function in cancer progression (43-45). Within a tumor, the tissue structure becomes disordered and the ECM is remodeled by mesenchymal cells, including CAFs (46). CAFs serve fundamental functions in ECM remodeling, metabolic and immune reprogramming of the TME, and have a marked effect on adaptive resistance to chemotherapy. Numerous ECM and basement membrane constituents are produced by activated fibroblasts or myofibroblasts (47). Furthermore, myofibroblasts are a major source of ECM-degrading proteases, including MMPs, and serve a vital function in the contribution of ECM desmoplasia by expressing $\alpha$-SMA, an important marker for myofibroblasts, and serves as a prognostic marker in multiple types of cancer $(48,49)$. CAFs maintain the mesenchymal phenotype in breast cancer cells by producing linear bundles in the ECM, which is a radial alignment of type I collagen fibers relative to tumors associated with local invasion and poor disease-free survival (DFS) (50). Furthermore, the ECM may be modified by interstitial flow and enzymes including lipoxygenase, which is secreted by CAFs. It has been demonstrated previously that CAFs are able to express a wide range of factors including cytokines, growth factors and chemokines, all of which are critical to induce the degradation of the ECM, promote angiogenesis and EMT, regulate metabolic reprogramming, and increase proliferation rates and chemotherapy resistance (51). In GC, invading the surrounding tissue and the ECM via enzymatic degradation is the first step of migration away from the primary tumor (52).
CAFs associated with GC stage. Cancer is associated with fibroblasts throughout all stages of disease progression, including metastasis, and CAFs are a key component of the general host response to tissue damage caused by cancer cells $(12,53)$. CAFs are activated and respond to cross-talk with cancer cells during carcinogenesis, and create a suitable niche for tumor growth and metastasis (54). A previous study has demonstrated that the quantity of CAFs in tumor stroma is associated with the stage of the tumor and may provide prognostic information (55). Shan et al (56) demonstrated the association between quantitative levels of FAP in GC stromal and clinicopathological characteristics. FAPs are secreted by CAFs and act as a regulator of GC cell invasion and migration, and are highly expressed in advanced-stage disease (stages III-IV). FAP expression is markedly increased in patients with lymph node involvement and metastases compared with patients without metastases. Furthermore, the study also demonstrated that stromal fibroblasts from the GC invasion front (the interface zone fibroblasts) had a marked positive FAP expression compared with NFs and CAFs (56).

It has been demonstrated previously that the predominant cell type in desmoplastic tumor is CAFs (57). De Monte et al (58) demonstrated the association between the quantity of Thelper cell (Th) 2 and Th1 tumor immune infiltrate present in the tumor stroma, and determined a poor prognosis in patients with pancreatic cancer who had R0 or R1 resection at stage IB-III. In addition, it was demonstrated that the CAFs 


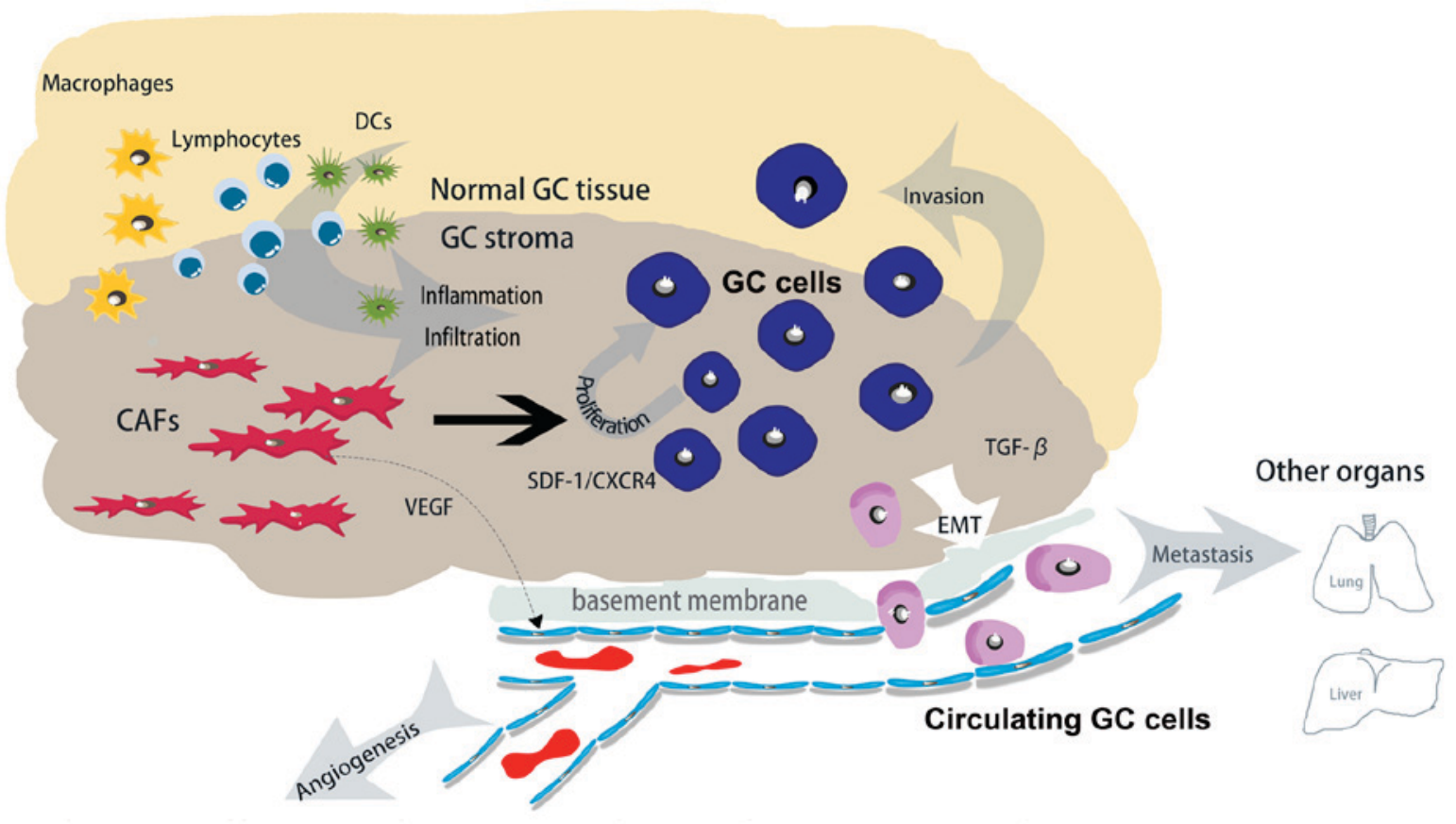

Figure 2. Role of CAFs in GC stroma. Compared with normal GC tissues, GC cancer stroma contains many CAFs and secretes various functional molecules. CAFs promote angiogenesis by secreting VEGF, and promote GC cell proliferation and metastasis by secreting SDF- 1 and TGF- $\beta 1$, respectively. Therefore, the direct action of CAFs may be able to mediate the infiltration of immune cells into the cancer stroma for a sustained anticancer immune response. CAFs, cancer-associated fibroblasts; GC, gastric cancer; VEGF, vascular endothelial growth factor; SDF-1, stromal cell-derived factor 1; TGF- $\beta 1$, transforming growth factor $\beta 1$; CXCR4, C-X-C chemokine receptor type 4; EMT, epithelial-mesenchymal transition; DCs, dendritic cells.

served a significant function in Th2 immune deviation, which led to the secretion of thymic stromal lymphopoietin (TSLP) and activated myeloid dendritic cells (DCs) with features of TSLP-conditioned DCs with Th2-polarizing capability. Berdiel-Acer et al (59) observed the fibroblast migratory potential between normal colonic fibroblasts (NCFs) obtained from normal colonic mucosa between 5 and $10 \mathrm{~cm}$ from the surgical margin, and CAFs from primary tumors and hepatic metastasis (CAF-LM) obtained from fresh liver metastases. Results demonstrated that the transcriptomic signature of fibroblasts, which were defined in the study, was able to function as an independent predictor of patient outcome and facilitate the selection of patients at risk of disease recurrence, particularly high-risk patients. Furthermore, genetic analysis demonstrated that the ZEB1, SNAI1, SLUG1, E-cadherin and N-cadherin genes exhibited a gradual increase in expression during cancer progression from ECM to liver metastasis, which may regulate CAF-LM to induce EMT phenotypes in epithelial cells more efficiently compared with other types of myofibroblasts.

CAFs promote pathological angiogenesis in GC. Pathological angiogenesis is a hallmark of cancer (60). Growth, invasion and metastasis of malignant tumors, including GC, depend upon microvessels that are regulated by pro-angiogenic and anti-angiogenic factors $(61,62)$. The degree of tumor angiogenesis is associated with clinical outcome and as angiogenic properties are associated with tumor aggressiveness $(63,64)$. CAFs serve critical functions in cancer progression by inducing the remodeling of ECM, facilitating EMT, regulating metabolic reprogramming and also promoting angiogenesis $(65,66)$. Accumulating evidence has demonstrated that the secretion of chemokines by CAFs may assist in recruiting bone marrow-derived angiogenic cells (67). CAFs are a major source of angiogenic factors including VEGF, angiopoietin 1, basic fibroblast proliferation factor, TGF- $\beta 1$, PDGF, tumor necrosis factor $\alpha$, hepatocyte growth factor, insulin-like growth factor-1 and monocyte chemoattractant protein-1 (MCP-1) $(68,69)$. Accumulating evidence demonstrated that hypoxia serves a critical function in the angiogenic process of GC by upregulating the secretion of angiogenic factors from CAFs, including VEGF and angiopoietin $(53,67,70,71)$. Additionally, angiogenesis at the primary and metastatic site may be associated with SDF-1 and thrombospondin-1 secretion from CAFs $(66,72)$. It has also been demonstrated that Gal-1 is highly expressed in GC CAFs, which is also associated with VEGF and CD31 expression, resulting in the promotion of tumor growth and angiogenesis (73). Hara et al (74) demonstrated that itraconazole modulated the suppression of CAFs and endothelial cells in bevacizumab-resistant gastrointestinal cancer cell lines (HT-29, MKN-28 and MKN-45), human umbilical vein endothelial cells and modulated the suppression of CAFs in human colon cancer. Bai et al (75) demonstrated that the overexpression of FGF-1/-3 was increased compared with NFs and pericarcinoma fibroblasts (PFs) in human colon cancer, leading to an increase in the rate of angiogenesis and the formation of a tumor accompanied by an increase in MMP-7 and mitogen-activated protein kinase/ERK production.

CAFs promote immune cell infiltration in GC. Previous studies have demonstrated that the inflammatory status and the immune microenvironment promote the progression of cancer (76-78). Numerous studies have demonstrated that inflammatory cells, mediators (including chemokines and TNF- $\alpha /$ IL-1 $\beta$ ) and key transcription factors are present in 
the cancer TME in experimental animal models and human tissues (79-81). Notably, simultaneous acute recruitment of immune cell infiltration and fibrosis has been reported previously, which may demonstrate the association between CAF and the immune microenvironment $(82,83)$.

The coevolution between cancer cells and stromal cells increases the number of inflammatory mediators and leads to the formation of a cancer-associated immune microenvironment $(79,84,85)$. There have been previous attempts to classify the tumor stroma into three groups, Collagen-dominant, fibroblast-dominant or lymphocyte-dominant, on the basis of the stromal status. Notably, the dominant stromal type may serve as an independent predictor of DFS, particularly in patients with high-grade tumors. Furthermore, lymphocyte-dominant types predicted the longest DFS compared with the two other types; this suggested that lymphocytic infiltration is associated with a favorable prognosis $(83,86-88)$. Notably, a previous study (89) has provided evidence that CAFs produce pro-inflammatory factors including IL-6, cyclooxygenase 2 (COX-2) and CXC chemokine ligand 1 that drive leukocyte infiltration. Thus, CAFs may promote tumor progression by facilitating immune cell infiltration. Macrophages are derived from $\mathrm{CD} 34^{+}$bone marrow progenitors which continually proliferate and differentiate into specific types of resident tissue macrophages, and are prominent components in the stroma accounting for almost all types of malignancy (90). Additionally, macrophages at the tumor periphery are able to foster local invasion by supplying matrix-degrading enzymes, including MMPs and cysteine cathepsin proteases (91). It has been demonstrated previously that tumor-associated macrophage (TAM) infiltration is associated with poor prognostic features, higher tumor grades and decreased DFS in patients with cancer (91-93). Herrera et al (94) demonstrated that the combination of CAFs and M2 macrophages were associated with poor disease-free survival and overall survival rates in advanced-stage patients, and also provided evidence of the prognostic potential of combining these two cells types of cell. The mechanism of action described previously indicated that histidine-rich glycoprotein suppressed placental growth factor-dependent polarization of the tumor immune environment, and regulated the suppression of macrophages from a pro-tumor (M2) to an anti-tumor (M1) phenotype (95). VEGF, secreted by CAFs, served an immunosuppressive function by affecting $\mathrm{T}$-cell progenitors and leading to an increase in the infiltration of regulatory $\mathrm{T}$ cells and myeloid-derived suppressor cells, triggering immunosuppression (96). When investigating the function of CAF-rich desmoplastic stroma in pancreatic ductal adenocarcinoma, results demonstrated that there was an increase in the number of inflammatory markers including MCP-1, also termed chemokine ligand (CCL) 2 (CCL20, TGF $\beta$, indoleamine-pyrrole 2,3-dioxygenase, IL-6 and COX-2 were also identified) (97). MCP-1 is a well-characterized chemokine involved in attracting macrophages into the TME, and inducing the differentiation of macrophages into an immunosuppressive M2 type (98). CAFs that are isolated from pre-neoplastic skin lesions expressed a pro-inflammatory gene signature and promoted macrophage recruitment in vivo in an $\mathrm{NF- \kappa B}-$ dependent manner (99). It has been previously demonstrated that CCL2 and CXCL14 (secretions from CAFs) are able to increase the recruitment of macrophages and promote their intravasive ability $(100,101)$.
A previous study also demonstrated that TGF- $\beta$ (a product of TAMs and MDSCs including CAFs) possesses the ability to improve the phagocytic ability of TAMs and limit the ability of DC to internalize, present the antigen and transport the antigen to the draining lymphatic system (102). Additionally, TGF- $\beta$ attenuated interferon- $\gamma$ secretion by natural killer (NK) cells, resulting in the impairment of Th1 differentiation, and inhibited the expression of NK cell-activating receptors including NK group 2, member D, NKp6, NKp44 and NKp30 (103,104). Essentially, the direct action of CAFs may be able to mediate the infiltration of immune cells for a sustained anticancer immune response (Fig. 2).

\section{Conclusion and prospects}

CAFs are an important component in the TME in GC, the research of which is becoming increasingly important. In the present review, the potential origin of CAFs in GC, their distinctive secretions that may be used to identify CAFs and how CAFs are able to influence GC progression have been discussed. The studies discussed in the present review demonstrate that CAFs may modulate several aspects of tumor biological behavior in GC including the ability to proliferate, metastasize and invade. Additionally, CAFs increase the infiltration of immune cells into GC stroma and increase the rate of angiogenesis by secreting VEGF. However, further investigation is required in order to determine the precise origin of CAFs in GC and the mechanisms underlying the role of CAFs in regulating the evolution of cancer cells in GC.

\section{Acknowledgements}

The present review was supported by the Science Fund of the National Natural Science Foundation of China (grant nos. 81401515 and 81230031), the Fundamental Research Funds for the Central Universities of Ministry of Education of China (grant no. 2042014kf0096) and the 351 Talent Project (Luojia Young Scholars) of Wuhan University.

\section{References}

1. Chen W, Zheng R, Baade PD, Zhang S, Zeng H, Bray F, Jemal A, Yu XQ and He J: Cancer statistics in China, 2015. CA Cancer J Clin 66: 115-132, 2016.

2. Wong $\mathrm{H}$ and Yau T: Targeted therapy in the management of advanced gastric cancer: Are we making progress in the era of personalized medicine? Oncologist 17: 346-358, 2012.

3. Suzuki HI, Katsura A, Matsuyama H and Miyazono K: MicroRNA regulons in tumor microenvironment. Oncogene 34: 3085-3094, 2015

4. Peng CW, Tian Q, Yang GF, Fang M, Zhang ZL, Peng J, Li Y and Pang DW: Quantum-dots based simultaneous detection of multiple biomarkers of tumor stromal features to predict clinical outcomes in gastric cancer. Biomaterials 33: 5742-5752, 2012.

5. Lee K, Hwang H and Nam KT: Immune response and the tumor microenvironment: How they communicate to regulate gastric cancer. Gut Liver 8: 131-139, 2014.

6. Kim JW, Nam KH, Ahn SH, Park DJ, Kim HH, Kim SH, Chang H, Lee JO, Kim YJ, Lee HS, et al: Prognostic implications of immunosuppressive protein expression in tumors as well as immune cell infiltration within the tumor microenvironment in gastric cancer. Gastric Cancer 19: 42-52, 2016.

7. Lauren P: The two histological main types of gastric carcinoma: Diffuse and so-called intestinal-type carcinoma. An attempt at a histo-clinical classification. Acta Pathol Microbiol Scand 64: 31-49, 1965. 
8. Kim MG, Shon Y, Kim J and Oh YK: Selective activation of anticancer chemotherapy by cancer-associated fibroblasts in the tumor microenvironment. J Natl Cancer Inst 109: pii: djw186, 2017.

9. Kanemaru A, Yamamoto K, Kawaguchi M, Fukushima T, Lin CY, Johnson MD, Camerer E and Kataoka H: Deregulated matriptase activity in oral squamous cell carcinoma promotes the infiltration of cancer-associated fibroblasts by paracrine activation of protease-activated receptor 2 . Int J Cancer 140 : 130-141, 2017.

10. Ouyang L, Chang W, Fang B, Qin J, Qu X and Cheng F: Estrogen-induced SDF-1 $\alpha$ production promotes the progression of ER-negative breast cancer via the accumulation of MDSCs in the tumor microenvironment. Sci Rep 6: 39541, 2016.

11. Karimi P, Islami F, Anandasabapathy S, Freedman ND and Kamangar F: Gastric cancer: Descriptive epidemiology, risk factors, screening and prevention. Cancer Epidemiol Biomarkers Prev 23: 700-713, 2014

12. Quante M, Tu SP, Tomita H, Gonda T, Wang SS, Takashi S, Baik GH, Shibata W, Diprete B and Betz KS, et al: Bone marrow-derived myofibroblasts contribute to the mesenchymal stem cell niche and promote tumor growth. Cancer cell 19 257-272, 2011

13. Räsänen $\mathrm{K}$ and Vaheri A: Activation of fibroblasts in cancer stroma. Exp Cell Res 316: 2713-2722, 2010

14. Yang J, Lu Y, Lin YY, Zheng ZY, Fang JH, He S and Zhuang SM: Vascular mimicry formation is promoted by paracrine TGF- $\beta$ and SDF1 of cancer-associated fibroblasts and inhibited by miR-101 in hepatocellular carcinoma. Cancer Lett 383: 18-27, 2016.

15. Xia Q, Zhang FF, Geng F, Liu CL, Wang YQ, Xu P, Lu ZZ, Xie Y, $\mathrm{Wu} \mathrm{H}$, Chen $\mathrm{Y}$, et al: Improvement of anti-tumor immunity of fibroblast activation protein $\alpha$ based vaccines by combination with cyclophosphamide in a murine model of breast cancer. Cell Immunol 310: 89-98, 2016.

16. Polanska UM and Orimo A: Carcinoma-associated fibroblasts: Non-neoplastic tumour-promoting mesenchymal cells. J Cell Physiol 228: 1651-1657, 2013.

17. Maeda K, Chung YS, Ogawa Y, Takatsuka S, Kang SM, Ogawa M, Sawada T and Sowa M: Prognostic value of vascular endothelial growth factor expression in gastric carcinoma. Cancer 77: 858-863, 1996.

18. Terai S, Fushida S, Tsukada T, Kinoshita J, Oyama K, Okamoto K, Makino I, Tajima H, Ninomiya I, Fujimura T, et al: Bone marrow derived 'fibrocytes' contribute to tumor proliferation and fibrosis in gastric cancer. Gastric Cancer 18: 306-313, 2015.

19. Yang TS, Yang XH, Chen X, Wang XD, Hua J, Zhou DL, Zhou B and Song ZS: MicroRNA-106b in cancer-associated fibroblasts from gastric cancer promotes cell migration and invasion by targeting PTEN. FEBS Lett 588: 2162-2169, 2014

20. Gu J, Qian H, Shen L, Zhang X, Zhu W, Huang L, Yan Y, Mao F, Zhao C, Shi Y and Xu W: Gastric cancer exosomes trigger differentiation of umbilical cord derived mesenchymal stem cells to carcinoma-associated fibroblasts through TGF- $\beta /$ Smad pathway. PloS one 7: e52465, 2012

21. Fuyuhiro Y, Yashiro M, Noda S, Kashiwagi S, Matsuoka J, Doi Y, Kato Y, Hasegawa T, Sawada T and Hirakawa K: Upregulation of cancer-associated myofibroblasts by TGF- $\beta$ from scirrhous gastric carcinoma cells. Brit J Cancer 105: 996-1001, 2011.

22. Han ME, Kim HJ, Shin DH, Hwang SH, Kang CD and Oh SO Overexpression of NRG1 promotes progression of gastric cancer by regulating the self-renewal of cancer stem cells. J Gastroenterol 50: 645-656, 2015.

23. Kikuchi Y, Kunita A, Iwata C, Komura D, Nishiyama T, Shimazu K, Takeshita K, Shibahara J, Kii I, Morishita Y, et al: The niche component periostin is produced by cancer-associated fibroblasts, supporting growth of gastric cancer through ERK activation. Am J Pathol 184: 859-870, 2014.

24. Goetz JG, Minguet S, Navarro-Lérida I,Lazcano JJ, Samaniego R, Calvo E, Tello M, Osteso-Ibáñez T, Pellinen T, Echarri A, et al: Biomechanical remodeling of the microenvironment by stroma caveolin-1 favors tumor invasion and metastasis. Cell 146 148-163, 2011.

25. Erez N, Truitt M, Olson P, Arron ST and Hanahan D: Cancer-associated fibroblasts are activated in incipient neoplasia to orchestrate tumor-promoting inflammation in an NF-kappaB-dependent manner. Cancer cell 17: 135-147, 2010.

26. Semba S, Kodama Y, Ohnuma K, Mizuuchi E, Masuda R, Yashiro M, Hirakawa K and Yokozaki H: Direct cancer-stroma interaction increases fibroblast proliferation and enhances invasive properties of scirrhous-type gastric carcinoma cells. Brit J Cancer 101: 1365-1373, 2009.
27. Tsukada T, Fushida S, Harada S, Yagi Y, Kinoshita J, Oyama K, Tajima H, Fujita H, Ninomiya I, Fujimura T and Ohta T: The role of human peritoneal mesothelial cells in the fibrosis and progression of gastric cancer. Int J Oncol 41: 476-482, 2012.

28. Fukui H, Zhang X, Sun C, Hara K, Kikuchi S, Yamasaki T, Kondo T, Tomita T, Oshima T, Watari J, et al: IL-22 produced by cancer-associated fibroblasts promotes gastric cancer cell invasion via STAT3 and ERK signaling. Br J Cancer 111: 763-771, 2014.

29. He XJ, Tao HQ, Hu ZM, Ma YY, Xu J, Wang HJ, Xia YJ, Li L, Fei BY, Li YQ and Chen JZ: Expression of galectin-1 in carcinoma-associated fibroblasts promotes gastric cancer cell invasion through upregulation of integrin $\beta 1$. Cancer Sci 105: 1402-1410, 2014

30. Sun C, Fukui H, Hara K, Zhang X, Kitayama Y, Eda H, Tomita T, Oshima T, Kikuchi S, Watari J, et al: FGF9 from cancer-associated fibroblasts is a possible mediator of invasion and anti-apoptosis of gastric cancer cells. BMC Cancer 15: 333, 2015.

31. Sung CO, Lee KW, Han S and Kim SH: Twistl is up-regulated in gastric cancer-associated fibroblasts with poor clinical outcomes. Am J Pathol 179: 1827-1838, 2011.

32. Song YH, Zhu YT, Ding J, Zhou FY, Xue JX, Jung JH, Li ZJ and Gao WY: Distribution of fibroblast growth factors and their roles in skin fibroblast cell migration. Mol Med Rep 14: 3336-3342, 2016.

33. Zhang X, Ibrahimi OA, Olsen SK, Umemori H, Mohammadi M and Ornitz DM: Receptor specificity of the fibroblast growth factor family. The complete mammalian FGF family. J Biol Chem 281: 15694-15700, 2006.

34. Basilico C and Moscatelli D: The FGF family of growth factors and oncogenes. Adv Cancer Res 59: 115-165, 1992.

35. Cao H, Xu W, Qian H, Zhu W, Yan Y, Zhou H, Zhang X, Xu X Li J, Chen Z and Xu X: Mesenchymal stem cell-like cells derived from human gastric cancer tissues. Cancer Lett 274: 61-71, 2009.

36. Karnoub AE, Dash AB, Vo AP, Sullivan A, Brooks MW, Bell GW, Richardson AL, Polyak K, Tubo R and Weinberg RA: Mesenchymal stem cells within tumour stroma promote breast cancer metastasis. Nature 449: 557-563, 2007.

37. Xu X, Zhang X, Wang S, Qian H, Zhu W, Cao H, Wang M, Chen Y and $\mathrm{Xu} \mathrm{W}$ : Isolation and comparison of mesenchymal stem-like cells from human gastric cancer and adjacent non-cancerous tissues. J Cancer Res Clin Oncol 137: 495-504, 2011.

38. Ponta $\mathrm{H}$, Sherman L and Herrlich PA: CD44: From adhesion molecules to signalling regulators. Nat Rev Mol Cell Biol 4: 33-45, 2003.

39. Yu B, Chen X, Li J, Qu Y, Su L, Peng Y, Huang J, Yan J, Yu Y, $\mathrm{Gu} \mathrm{Q}$, et al: Stromal fibroblasts in the microenvironment of gastric carcinomas promote tumor metastasis via upregulating TAGLN expression. BMC Cell Biol 14: 17, 2013.

40. Shimoda M, Mellody KT and Orimo A: Carcinoma-associated fibroblasts are a rate-limiting determinant for tumour progression. Semin Cell Dev Biol 21: 19-25, 2010.

41. Bourget JM, Gauvin R, Larouche D, Lavoie A, Labbé R, Auger FA and Germain L: Human fibroblast-derived ECM as a scaffold for vascular tissue engineering. Biomaterials 33: 9205-9213, 2012.

42. Venning FA, Wullkopf L and Erler JT: Targeting ECM disrupts cancer progression. Front Oncol 5: 224, 2015.

43. Pickup MW, Mouw JK and Weaver VM: The extracellular matrix modulates the hallmarks of cancer. EMBO Rep 15: 1243-1253, 2014.

44. Bonnans C, Chou J and Werb Z: Remodelling the extracellular matrix in development and disease. Nat Rev Mol Cell Biol 15: 786-801, 2014.

45. Egeblad M and Werb Z: New functions for the matrix metalloproteinases in cancer progression. Nat Rev Cancer 2: 161-174, 2002.

46. Carmeliet P: Angiogenesis in life, disease and medicine. Nature 438: 932-936, 2005.

47. Kalluri R: The biology and function of fibroblasts in cancer. Nat Rev Cancer 16: 582-598, 2016.

48. Simian M, Hirai Y, Navre M, Werb Z, Lochter A and Bissell MJ: The interplay of matrix metalloproteinases, morphogens and growth factors is necessary for branching of mammary epithelial cells. Development 128: 3117-3131, 2001.

49. Tsujino T, Seshimo I, Yamamoto H, Ngan CY, Ezumi K, Takemasa I, Ikeda M, Sekimoto M, Matsuura N and Monden M: Stromal myofibroblasts predict disease recurrence for colorectal cancer. Clin Cancer Res 13: 2082-2090, 2007.

50. Sugimoto H, Mundel TM, Kieran MW and Kalluri R: Identification of fibroblast heterogeneity in the tumor microenvironment. Cancer Biol Ther 5: 1640-1646, 2006. 
51. Erkan M, Michalski CW, Rieder S, Reiser-Erkan C, Abiatari I, Kolb A, Giese NA, Esposito I, Friess H and Kleeff J: The activated stroma index is a novel and independent prognostic marker in pancreatic ductal adenocarcinoma. Clin Gastroenterol Hepatol 6: 1155-1161, 2008.

52. Shieh AC, Rozansky HA, Hinz B and Swartz MA: Tumor cell invasion is promoted by interstitial flow-induced matrix priming by stromal fibroblasts. Cancer Res 71: 790-800, 2011.

53. Crawford Y, Kasman I, Yu L, Zhong C, Wu X, Modrusan Z, Kaminker J and Ferrara N: PDGF-C mediates the angiogenic and tumorigenic properties of fibroblasts associated with tumors refractory to anti-VEGF treatment. Cancer Cell 15: 21-34, 2009.

54. Lazennec $\mathrm{G}$ and Richmond A: Chemokines and chemokine receptors: New insights into cancer-related inflammation. Trends Mol Med 16: 133-144, 2010.

55. Valcz G, Sipos F, Tulassay Z, Molnar B and Yagi Y: Importance of carcinoma-associated fibroblast-derived proteins in clinical oncology. J Clin Pathol 67: 1026-1031, 2014.

56. Shan LH, Sun WG, Han W, Qi L, Yang C, Chai CC, Yao K, Zhou QF, Wu HM, Wang LF and Liu JR: Roles of fibroblasts from the interface zone in invasion, migration, proliferation and apoptosis of gastric adenocarcinoma. J Clin Pathol 65: 888-895, 2012.

57. Elenbaas B and Weinberg RA: Heterotypic signaling between epithelial tumor cells and fibroblasts in carcinoma formation. Exp Cell Res 264: 169-184, 2001.

58. De Monte L, Reni M, Tassi E, Clavenna D, Papa I, Recalde H, Braga M, Di Carlo V, Doglioni C and Protti MP: Intratumor T helper type 2 cell infiltrate correlates with cancer-associated fibroblast thymic stromal lymphopoietin production and reduced survival in pancreatic cancer. J Exp Med 208: 469-478, 2011.

59. Berdiel-Acer M, Bohem ME,López-Doriga A, Vidal A, Salazar R, Martínez-Iniesta M, Santos C, Sanjuan X, Villanueva A and Molleví DG: Hepatic carcinoma-associated fibroblasts promote an adaptative response in colorectal cancer cells that inhibit proliferation and apoptosis: Nonresistant cells die by nonapoptotic cell death. Neoplasia 13: 931-946, 2011.

60. Carmeliet P and Jain RK: Angiogenesis in cancer and other diseases. Nature 407: 249-257, 2000.

61. Poon RT, Fan ST and Wong J: Clinical implications of circulating angiogenic factors in cancer patients. J Clin Oncol 19: $1207-1225,2001$.

62. Folkman J: What is the evidence that tumors are angiogenesis dependent? J Natl Cancer Inst 82: 4-6, 1990.

63. Weidner N, Carroll PR, Flax J, Blumenfeld W and Folkman J: Tumor angiogenesis correlates with metastasis in invasive prostate carcinoma. Am J Pathol 143: 401-409, 1993.

64. Weidner N, Folkman J, Pozza F, Bevilacqua P, Allred EN Moore DH, Meli S and Gasparini G: Tumor angiogenesis: A new significant and independent prognostic indicator in early-stage breast carcinoma. J Natl Cancer Inst 84: 1875-1887, 1992

65. Hayashi Y, Tsujii M, Akasaka T, Kato M, Inoue T, Tsujii Y, Maekawa A, Shinzaki S, Nishida T, Watabe K, et al: Carcinoma-associated fibroblasts educated by P53-Incompetent cancer cells contribute tumor growth through angiogenesis. Gastroenterol 146 (Suppl): S488-S489, 2014.

66. Orimo A and Weinberg RA: Stromal fibroblasts in cancer: A novel tumor-promoting cell type. Cell Cycle 5: 1597-1601, 2006.

67. De Francesco EM, Lappano R, Santolla MF, Marsico S, Caruso A and Maggiolini M: HIF-1 $\alpha /$ GPER signaling mediates the expression of VEGF induced by hypoxia in breast cancer associated fibroblasts (CAFs). Breast Cancer Res 15: R64, 2013.

68. Li H, Adachi Y, Yamamoto H, Min Y, Ohashi H, Ii M, Arimura Y, Endo T, Lee CT, Carbone DP, et al: Insulin-like growth factorreceptor blockade reduces tumor angiogenesis and enhances the effects of bevacizumab for a human gastric cancer cell line, MKN45. Cancer 117: 3135-3147, 2011.

69. Pinedo HM, Verheul HM, D'Amato RJ and Folkman J: Involvement of platelets in tumour angiogenesis? Lancet 352 1775-1777, 1998

70. Bilen MA, Zurita AJ, Ilias-Khan NA, Chen HC, Wang X, Kearney AY, Hodges S, Jonasch E, Huang S, Khakoo AY and Tannir NM: Hypertension and circulating cytokines and angiogenic factors in patients with advanced non-clear cell renal cell carcinoma treated with sunitinib: results from a phase II trial. Oncologist 20: 1140-1148, 2015.

71. Taddei ML, Giannoni E, Comito $G$ and Chiarugi $P$ : Microenvironment and tumor cell plasticity: An easy way out. Cancer Lett 341: 80-96, 2013.
72. Hellevik T, Pettersen I, Berg V, Bruun J, Bartnes K, Busund LT, Chalmers A, Bremnes R and Martinez-Zubiaurre I: Changes in the secretory profile of NSCLC-associated fibroblasts after ablative radiotherapy: Potential impact on angiogenesis and tumor growth. Transl Oncol 6: 66-74, 2013.

73. Tang D, Gao J, Wang S, Ye N, Chong Y, Huang Y, Wang J, Li B, Yin W and Wang D: Cancer-associated fibroblasts promote angiogenesis in gastric cancer through galectin-1 expression. Tumour Biol 37: 1889-1899, 2016.

74. Hara M, Nagasaki T, Shiga K and Takeyama H: Suppression of cancer-associated fibroblasts and endothelial Cells by itraconazole in bevacizumab-resistant gastrointestinal cancer. Anticancer Res 36: 169-177, 2016.

75. Bai YP, Shang K, Chen H, Ding F, Wang Z, Liang C, Xu Y, Sun MH and Li YY: FGF-1/-3/FGFR4 signaling in cancer-associated fibroblasts promotes tumor progression in colon cancer through Erk and MMP-7. Cancer Sci 106: 1278-1287, 2015.

76. Uso M, Jantus-Lewintre E, Bremnes RM, Calabuig S, Blasco A, Pastor E, Borreda I, Molina-Pinelo S, Paz-Ares L and Guijarro R: Analysis of the immune microenvironment in resected non-small cell lung cancer: The prognostic value of different $\mathrm{T}$ lymphocyte markers. Oncotarget 7: 52849-52861, 2016.

77. $\mathrm{He} \mathrm{J}, \mathrm{Hu}$ Y, Hu M and Li B: Development of PD-1/PD-L1 Pathway in tumor immune microenvironment and treatment for non-small cell lung cancer. Sci Rep 5: 13110, 2015.

78. Whiteside TL: Apoptosis of immune cells in the tumor microenvironment and peripheral circulation of patients with cancer: Implications for immunotherapy. Vaccine 20 (Suppl 4): A46-A51, 2002.

79. Mantovani A, Allavena P, Sica A and Balkwill F: Cancer-related inflammation. Nature 454: 436-444, 2008.

80. Flossmann E and Rothwell PM; British Doctors Aspirin Trial and the UK-TIA Aspirin Trial: Effect of aspirin on long-term risk of colorectal cancer: Consistent evidence from randomised and observational studies. Lancet 369: 1603-1613, 2007.

81. Chan AT, Ogino S and Fuchs CS: Aspirin and the risk of colorectal cancer in relation to the expression of COX-2. N Engl J Med 356: 2131-2142, 2007.

82. Haviv I, Polyak K, Qiu W, Hu M and Campbell I: Origin of carcinoma associated fibroblasts. Cell Cycle 8: 589-595, 2009.

83. Sangai T, Ishii G, Kodama K, Miyamoto S, Aoyagi Y, Ito T, Magae J, Sasaki H, Nagashima T, Miyazaki M and Ochiai A: Effect of differences in cancer cells and tumor growth sites on recruiting bone marrow-derived endothelial cells and myofibroblasts in cancer-induced stroma. Int J Cancer 115: 885-892, 2005

84. De Falco V, Guarino V, Avilla E, Castellone MD, Salerno P, Salvatore G, Faviana P, Basolo F, Santoro M and Melillo RM: Biological role and potential therapeutic targeting of the chemokine receptor CXCR4 in undifferentiated thyroid cancer. Cancer Res 67: 11821-11829, 2007.

85. Borrello MG, Alberti L, Fischer A, Degl'innocenti D, Ferrario C, Gariboldi M, Marchesi F, Allavena P, Greco A, Collini P, et al: Induction of a proinflammatory program in normal human thyrocytes by the RET/PTC1 oncogene. Pro Natl Acad Scie USA 102: 14825-14830, 2005.

86. Ahn S, Cho J, Sung J, Lee JE, Nam SJ, Kim KM and Cho EY: The prognostic significance of tumor-associated stroma in invasive breast carcinoma. Tumour Biol 33: 1573-1580, 2012.

87. Martinet L, Garrido I, Filleron T, Le Guellec S, Bellard E, Fournie JJ, Rochaix P and Girard JP: Human solid tumors contain high endothelial venules: Association with T- and B-lymphocyte infiltration and favorable prognosis in breast cancer. Cancer Res 71: 5678-5687, 2011.

88. Rosenwald A, Wright G, Chan WC, Connors JM, Campo E, Fisher RI, Gascoyne RD, Muller-Hermelink HK, Smeland EB, Giltnane JM, et al: The use of molecular profiling to predict survival after chemotherapy for diffuse large-B-cell lymphoma. N Engl J Med 346: 1937-1947, 2002.

89. Erez N, Glanz S, Raz Y, Avivi C and Barshack I: Cancer associated fibroblasts express pro-inflammatory factors in human breast and ovarian tumors. Biochem Biophys Res Commun 437: 397-402, 2013

90. Lewis CE and Pollard JW: Distinct role of macrophages in different tumor microenvironments. Cancer Res 66: 605-612, 2006.

91. Laoui D, Movahedi K, Van Overmeire E, Van den Bossche J, Schouppe E, Mommer C, Nikolaou A, Morias Y, De Baetselier P and Van Ginderachter JA: Tumor-associated macrophages in breast cancer: Distinct subsets, distinct functions. Int J Dev Biol 55: 861-867, 2011 
92.Campbell MJ, Tonlaar NY, Garwood ER, Huo D, Moore DH, Khramtsov AI, Au A, Baehner F, Chen Y, Malaka DO, et al: Proliferating macrophages associated with high grade, hormone receptor negative breast cancer and poor clinical outcome. Breast Cancer Res Treat 128: 703-711, 2011.

93. Lee AH, Happerfield LC, Bobrow LG and Millis RR: Angiogenesis and inflammation in invasive carcinoma of the breast. J Clin Pathol 50: 669-673, 1997.

94. Herrera M, Herrera A, Dominguez G, Domínguez G, Silva J, García V, García JM, Gómez I, Soldevilla B, Muñoz C, Provencio $\mathrm{M}$, et al: Cancer-associated fibroblast and M2 macrophage markers together predict outcome in colorectal cancer patients. Cancer Sci 104: 437-444, 2013.

95. Rolny C, Mazzone M, Tugues S, Laoui D, Johansson I, Coulon C, Squadrito ML, Segura I, Li X, Knevels E, et al: HRG inhibits tumor growth and metastasis by inducing macrophage polarization and vessel normalization through downregulation of PlGF. Cancer Cell 19: 31-44, 2011.

96. Wada J, Suzuki H, Fuchino R, Yamasaki A, Nagai S, Yanai K, Koga K, Nakamura M, Tanaka M, Morisaki T and Katano M: The contribution of vascular endothelial growth factor to the induction of regulatory T-cells in malignant effusions. Anticancer Res 29: 881-888, 2009.

97. Tjomsland V, Spångeus A, Välilä J, Sandström P, Borch K, Druid H, Falkmer S, Falkmer U, Messmer D and Larsson M: Interleukin 1alpha sustains the expression of inflammatory factors in human pancreatic cancer microenvironment by targeting cancer-associated fibroblasts. Neoplasia 13: 664-675, 2011.
98. Roca H, Varsos ZS, Sud S, Craig MJ, Ying C and Pienta KJ: CCL2 and interleukin-6 promote survival of human CD11b+ peripheral blood mononuclear cells and induce M2-type macrophage polarization. J Biol Chem 284: 34342-34354, 2009.

99. Mantovani A: La mala educacion of tumor-associated macrophages: Diverse pathways and new players. Cancer cell 17: 111-112, 2010.

100. Tsuyada A, Chow A, Wu J, Somlo G, Chu P, Loera S, Luu T, Li AX, Wu X, Ye W, et al: CCL2 mediates cross-talk between cancer cells and stromal fibroblasts that regulates breast cancer stem cells. Cancer Res 72: 2768-2779, 2012.

101. Augsten M, Hägglöf C, Olsson E, Stolz C, Tsagozis P, Levchenko T, Frederick MJ, Borg A, Micke P, Egevad L and Ostman A: CXCL14 is an autocrine growth factor for fibroblasts and acts as a multi-modal stimulator of prostate tumor growth. Proc Natl Acad Sci USA 106: 3414-3419, 2009.

102. Byrne SN, Knox MC and Halliday GM: TGFbeta is responsible for skin tumour infiltration by macrophages enabling the tumours to escape immune destruction. Immunol Cell Biol 86: 92-97, 2008.

103. Bekeredjian-Ding I, Schäfer M, Hartmann E, Pries R, Parcina M, Schneider P, Giese T, Endres S, Wollenberg B and Hartmann G: Tumour-derived prostaglandin E and transforming growth factor-beta synergize to inhibit plasmacytoid dendritic cell-derived interferon-alpha. Immunology 128: 439-450, 2009.

104. Weber F, Byrne SN, Le S, Brown DA, Breit SN, Scolyer RA and Halliday GM: Transforming growth factor-betal immobilises dendritic cells within skin tumours and facilitates tumour escape from the immune system. Cancer Immunol Immunotherap 54: 898-906, 2005. 